\title{
Prospective comparison of charcoal swabs versus near-patient direct culture plate inoculation for the culture of gonorrhoea in high-risk patients
}

\author{
Annabelle Harrison, Hannah Cheney-Lowe, John McSorley, Siobhan Murphy, Gary Brook
}

Department of GUM/HIV Medicine, Central Middlesex Hospital, London, UK

\section{Background}

- Gonorrhoea culture is required to monitor antibiotic resistance and is recommended for all patients known or suspected to be infected.

- All patients at this clinic at high risk for GC (e.g. GNDP +ve on microscopy, GC contacts, untreated with a +ve GC NAAT) have a relevant sample sent for GC culture.

- Our laboratory service requested us to switch from nearpatient direct plating of high-risk swabs, to sending charcoal swabs urgently to the laboratory for plating in the lab (c. 2 hours later).

- Before agreeing to a switch we decided to send both charcoal swabs and near-patient directly plated culture plates and compare the results after sufficient samples had been sent.

\section{Methods}

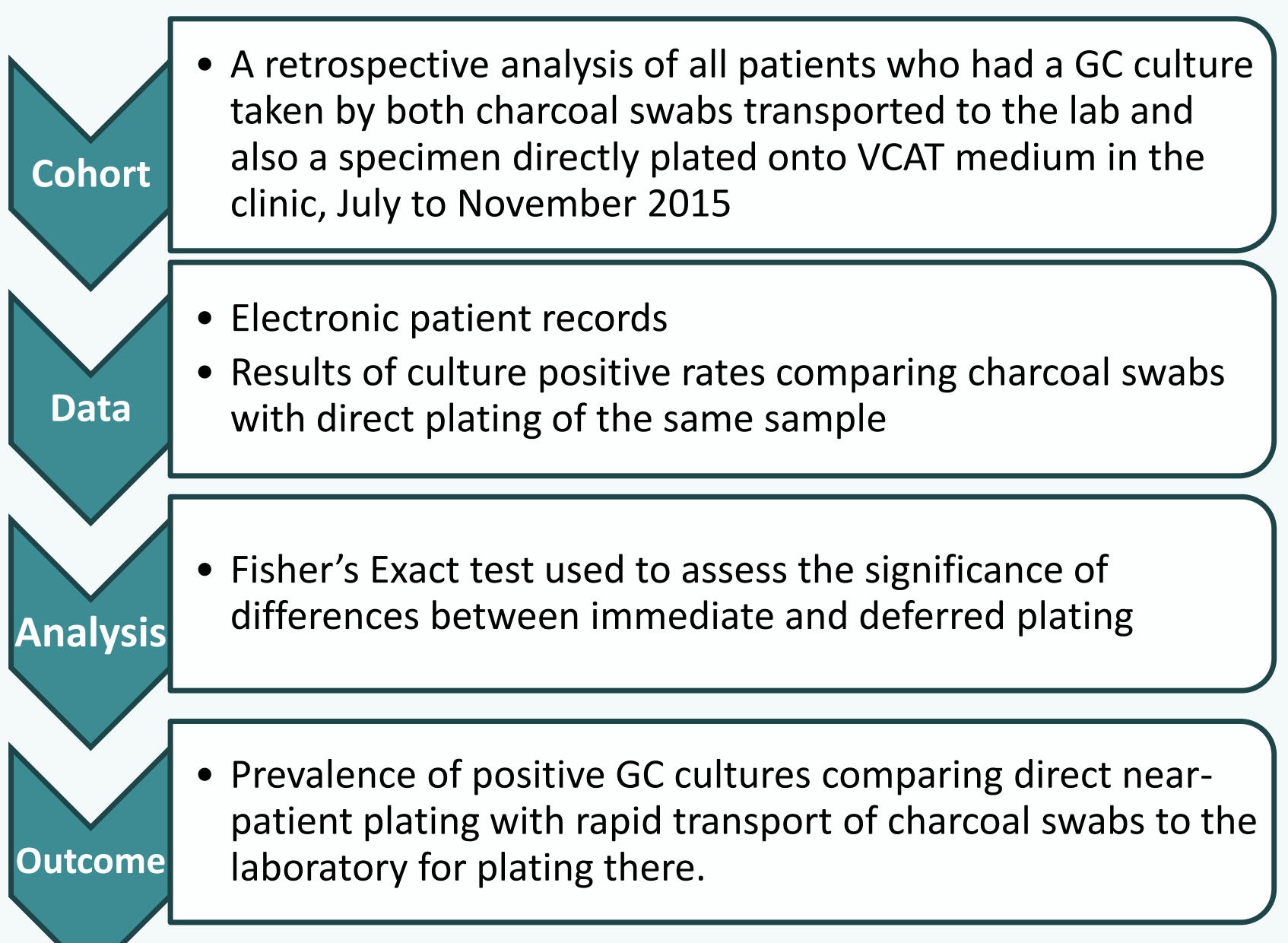

\section{Results}

Table - Prevalence of +ve GC cultures comparing direct plating with charcoal transport followed by deferred plating

\begin{tabular}{|c|c|c|c|c|}
\hline \multirow[b]{2}{*}{ Site * } & \multirow[b]{2}{*}{ Method } & \multicolumn{2}{|c|}{ GC Culture Result } & \multirow{2}{*}{$P$ value } \\
\hline & & Positive & Negative & \\
\hline \multirow{2}{*}{ All samples (61) } & Directly Plated & $41(67 \%)$ & $* * 20(33 \%)$ & \multirow{2}{*}{$<0.05$} \\
\hline & Charcoal Transport Medium & $31(51 \%)$ & $30(49 \%)$ & \\
\hline \multirow{2}{*}{ Male Urethra (34) } & Directly Plated & $29(85 \%)$ & $5(15 \%)$ & \multirow{2}{*}{$<0.05$} \\
\hline & Charcoal Transport Medium & $22(65 \%)$ & $12(35 \%)$ & \\
\hline \multirow{2}{*}{ Endocervical (14) } & Directly Plated & $7(50 \%)$ & $7(50 \%)$ & \multirow{2}{*}{ n.s. } \\
\hline & Charcoal Transport Medium & $6(43 \%)$ & $8(57 \%)$ & \\
\hline
\end{tabular}

\section{Discussion}

Microbiology labs have to comply with the government's UKAS accreditation system.

There is pressure on GUM clinics to stop direct-plating due to difficulties in meeting UKAS requirements

- Despite sending the charcoal swabs urgently to the laboratory and subsequent plating about 2 hours later, the culture-positive rate was $24 \%$ (10/41) lower than for nearpatient directly-plated specimens.

- This could not be explained through order of swabbing.

\section{Conclusion}

Our results showed that near-patient direct plating on VCAT medium was superior to charcoal swabs rapidly transported to the lab for GC culture.

Despite the problems around UKAS accreditation, nearpatient direct plating cannot be replaced by charcoal swabs sent to the laboratory . 